\title{
Migration Stress, Poor Mental Health, and Engagement in Sex with High-Risk Partners: A Mediation Modeling Analysis of Data from Rural-to-Urban Migrants in China
}

\author{
Bin $\mathrm{Yu}^{1}$, Xinguang Chen ${ }^{1,2}$, Yaqiong Yan², Jie Gong ${ }^{2}$, Fang $\mathrm{Li}^{2}$, and Emily Robserson ${ }^{1}$ \\ ${ }^{1}$ Department of Epidemiology, University of Florida, USA \\ ${ }^{2}$ Department of Chronic Disease, Wuhan Centers for Disease Prevention and Control, China
}

\begin{abstract}
Background-There is a growing need for better understanding of mechanisms underpinning the relationship between migration stress and HIV risk behaviors for the development of HIV prevention and control policy.

Methods-Survey data from a random sample of 1,293 Chinese rural-to-urban migrants were analyzed. Stress was assessed using the Domestic Migration Stress Questionnaire (DMSQ), mental health status was assessed using the Brief Symptoms Inventory (BSI), and having sex with high risk partners was assessed as if ever have had sex with high risk partners (e.g., sex workers, intravenous injection drug users, blood donors, persons infected with HIV, persons with sexually transmitted infection, and same gender partners) in the past year. The proposed relationship was tested using mediation modeling method.
\end{abstract}

Results-Among the sample, 5.5\% reported having had sex with high-risk partners in the past year. Mediation analysis indicated that the relationship between DMSQ scores and having sex with high-risk partners was mediated by BSI (coefficient $=0.41,95 \%$ CI $[0.21,0.65]$ ), including its components of somatization $(0.32[0.15,0.53])$, obsessive-compulsive disorder $(0.31[0.07,0.55])$, depression $(0.45[0.23,0.72])$, anxiety $(0.41[0.23,0.63])$, and hostility $(0.35[0.17,0.56])$.

Furthermore, the effect was more pronounced in males than in females.

Conclusion-The study findings provide new data advancing our understanding of the mechanism of engagement in risky sex, underscoring the need for the HIV prevention policies in China to pay more attention to mental health of the rural-to-urban migrant population.

\footnotetext{
Please address the correspondence to: Xinguang Chen, MD, PhD, Department of Epidemiology, University of Florida, 2004 Mowry Road, Gainesville, USA 32610, Tel: +01 352-294-5945, Fax:+01 352-273-5365, jimax.chen@ufl.edu.

Conflict of interest: The authors declare that they have no conflict of interest.

Compliance with Ethical Standards

Ethical approval: All procedures performed in studies involving human participants were in accordance with the ethical standards of the institutional and/or national research committee and with the 1964 Helsinki declaration and its later amendments or comparable ethical standards.

Informed consent: Informed consent was obtained from all individual participants included in the study.
} 


\section{Keywords}

Migration stress; Mental health status; HIV sexual risk behaviors; Mediation; Rural-to-urban migrants; HIV policies; China

\section{Introduction}

\section{Migration Stress and the Risk of HIV Infection}

There is a growing number of people who are migrating from rural areas to urban areas within a country and from less developed countries to more developed countries to pursue better opportunities (Berry, 1997; Chen, Yu, Gong, Zeng, \& MacDonell, 2015; Yu, Chen, \& $\mathrm{Li}, 2014)$. The process of migration is very stressful due to various expected and unexpected challenges and difficulties (Chen, Yu, Gong, et al., 2015; Weine \& Kashuba, 2012; Yu et al., 2014). Among various theories and models, two competing mechanisms are widely accepted in understanding migration-related stress: (1) Loneliness theory: Migration separates migrants from the place of origin, particularly their family and social contacts that remain in the origin. Therefore migrants often tend to stay with other migrants, particularly those from the same place of origin to avoid loneliness (Ponizovsky \& Ritsner, 2004). (2) Acculturation theory: when migrants adapt and assimilate into the host culture and lifestyle, they may feel being alienated and marginalized due to the experiences of discrimination and rejection (Berry, 1997). In this case, staying with migrants rather than people in the place of destination may in fact increase stress (Carpiano, Kelly, Easterbrook, \& Parsons, 2011; Chen, Yu, Gong, et al., 2015; Rudmin, 2003; Thomas, 1995).

These migration-related stresses may increase the likelihood for migrants to engage in health-risk behaviors as a way of coping, including tobacco smoking, alcohol use and abuse, and illicit drug use, and sexual risk behavior (Park, Anastas, Shibusawa, \& Nguyen, 2014; Yu et al., 2014). Engaging in risk sex plays a key role in HIV transmission. Empirical data from reported studies has shown that migration stress is positively associated with a number of sexual risk behaviors, including commercial sex, multiple sex partners, and inconsistent condom use, thus exposing migrants at increased risk for HIV infection (Sudhinaraset, Mmari, Go, \& Blum, 2012; T. Yang et al., 2009; X. Yang, Kelly, \& Yang, 2015).

\section{Migration Stress Associated with Poor Mental Health}

Stress has been demonstrated to be the strongest and most consistent predictor of poor mental health, including anxiety and depression (Cheung, 2014; Revollo, Qureshi, Collazos, Valero, \& Casas, 2011; Sirin, Ryce, Gupta, \& Rogers-Sirin, 2013; Yu et al., 2014). Migration stress is referred to the stress due to migration, including separation from the place of origin, rejection by people in the destination, lack of self-confidence, and Maladaptation to the destination (Chen, Yu, Gong, et al., 2015; Sirin et al., 2013). Findings from published studies demonstrated a positive association between migration stress and poor mental health among migrants, including somatic symptoms, obsessive-compulsive symptoms (Revollo et al., 2011), depression (Sirin et al., 2013), anxiety (Hovey \& Magana, 2000), and hostility (D. F. K. Wong \& Chang, 2010). A longitudinal study conducted among young migrants in New York showed that baseline stress was positively associated with 
somatic, anxious and depressed symptoms assessed in the follow-up (Sirin et al., 2013). However, few studies have ever tested the mediation role of poor mental health linking migration stress with HIV-related risk behaviors.

\section{Poor Mental Health Associated with HIV Risk Behaviors}

Research findings indicate that the prevalence rate of HIV infection among rural-to-urban migrants in China was 3.8/1000, 6.67 times higher than 0.57/1000, the rate of Chinese population in general (Zhang, Chow, Jahn, Kraemer, \& Wilson, 2013). Individuals with poor mental health status are more likely to engage in HIV sexual risk behaviors (Williams \& Latkin, 2005; H. Yang et al., 2005; X. Yang, 2006). These findings suggest that migrants may use sexual risk behavior as a coping response to reduce loneliness, relieve anxieties about family and work, and release frustration (Amirkhanian et al., 2011). However, engaging in sexual risk behaviors will exposes migrants to increased risk for HIV infection. For example, depression was reported to be positively associated with multi-partner sex among Puerto Rican migrants in New York and New Jersey (Deren, Kang, Mino, \& Guarino, 2010) and sexual risk taking among Central Asian migrants in Russia, and negative associated with condom use also among Central Asian migrants in Russia (Amirkhanian et al., 2011). A significant positive relationship between depression and unprotected casual sex was also reported among rural migrants in Southern China (X. Yang, 2006).

\section{Poor Mental Health May Mediate the Relationship between Migration Stress and HIV Sexual Risk Behaviors}

Although attention has been paid to the relationship between migration stress and poor mental health, as well as poor mental health and HIV-related risk behaviors, little has been done to investigate mechanisms that link migration stress to having sex with high risk partners. Engaging in risk and unprotected sex has been documented as a coping strategy to deal with stress in migrant (Du \& Li, 2015)and non-migrant populations (Brody, Chen, \& Kogan, 2010; Deuba et al., 2013; Folkman, Chesney, Pollack, \& Phillips, 1992; MuñozLaboy, Severson, \& Bannan, 2014). The research findings described in the previous sections suggest a potential mechanism by which poor mental health mediates the association between migration stress and sexual risk behaviors. However, no reported study has empirically investigated this mechanism. The number of rural-to-urban migrants in China currently totaling 270 million, is still growing (National Bureau of Statistics of the People's Republic of China, 2014). This large and growing population provides a window of opportunities to test this proposed mediation mechanism.

\section{Purpose of the Study}

Building upon previous research findings, the main purpose of this study is to test the hypothetic mechanism by which mental health status mediates the association between migration stress and HIV sexual risk behaviors. The ultimate goal is to provide new data advancing our understanding of the mechanisms underpinning HIV risk behavior among rural-to-urban migrant population, and to provide timely data supporting evidence-based policies and intervention programs for HIV prevention and control curb the growing HIV epidemic in China. 


\section{Materials and Methods}

\section{Participants and Sampling}

Data for this study were derived from the Migration and Behavioral Health Survey. Details regarding sampling and data collection were described elsewhere (Chen, Yu, Zhou, et al., 2015). This study targeted the rural-to-urban migrants as the study population. Migrants who met the following criteria were included: rural-to-urban migrants, 18 to 45 years old, selfreported as possessing a legal rural residence identity (Hukou), currently working in the city to earn money, having stayed in the city for at least one month, and having no plan to permanently relocate to the city as urban residents. Participants were recruited from Wuhan, the capital city of Hubei Province located in the central China. It consists of seven districts with a total population of 10 million and a per capita GDP of \$12,708 in 2012 (Statistical Bureau of Wuhan, 2012).

To obtain a non-biased and representative sample, the study participants were randomly selected from all urban districts of Wuhan with the assistance of the GIS/GPS technologies. The sampling method was established based upon previous studies (Landry \& Shen, 2005) with substantial improvement (Chen, Yu, Zhou, et al., 2015). Briefly, the geographic areas of Wuhan were first divided into mutually exclusive geographic units (named as geounits) with unit size of 100 by 100 meters. After exclusion of non-residential areas (i.e., lakes, streets, factories and public buildings), 60 geounits were randomly sampled on computer. More geounits were allocated to the districts with higher density of migrant population using the optimal design (Cochran, 1977; Grove, 2004; Spiegelman \& Gray, 1991) to enhance costeffectiveness. From each geounit, approximately 20 participants were randomly recruited from individual households (including apartments and dorms) with one participant per gender per household. For households with more than one eligible participant, one was selected using the random digit method.

Participants were recruited from the households located in the randomly selected geounits. With a de facto assumption, migrants at home during the survey period were approached. The households on the randomly selected geounits were diverse, including formal rental properties, dormitories provided by employers, street-side stands and stores as housing, and "the within-city villages" constructed by migrants themselves. To facilitate participant recruitment, assistance from local health workers and community group leaders who had close contact with and had established a good relationship with the migrants were obtained.

\section{Data Collection and Procedures}

Data collection was completed from March 2011 to December 2013. Wuhan Center for Disease Prevention and Control (CDC), the collaboration site in China was in charge of data collection. Prior to survey at a sampled geounit, a three-person team consisting of a CDC leader, a senior research staff, and a GIS/GPS expert went to the sampled geounit to make contact with the local community health center closest to the sampled geounit. The main purposes of this trip were to obtain support from the health center, to physically locate and assess the feasibility of the sampled geounit, and to make a plan for field data collection. 
On the scheduled survey day, a team of trained data collectors (senior research staff from Wuhan CDC and graduate students) went to the site to recruit participants and collect data. The Migrant Health and Behavior Survey, an anonymous instrument (Chen, Gong, et al., 2015; Chen, Stanton, Gong, Fang, \& Li, 2009) was used for data collection and the questionnaire was delivered through Audio Computer-Assisted Self Interviewing (ASACI). The survey was conducted in a designated room either in the local community health center, or in the participant's home, according to participant preference and the availability of spaces. Upon survey completion, each participant was provided material incentives equivalent to $\$ 5-6$.

The survey was well accepted. Among 1414 migrants approached, 1,293 (91.4\%) signed the informed consent and completed the survey. The data collected from these participants $(n=1293)$ were used for analysis in this study. The survey protocol was approved by the corresponding Institutional Review Boards (IRB) at Wuhan CDC, Wayne State University, and the University of Florida.

\section{Measures}

Outcome variable-Having sex with high risk partners in the past year - This variable was assessed based on participants' response to the question, "Have you ever engaged in sexual intercourse with any of the following persons in the past years?" A checklist of six categories of risk partners was provided: (1) sex workers, (2) intravenous injection drug users or IDU, (3) commercial blood donors, (4) persons infected with HIV, (5) persons with sexually transmitted infection, and (6) same gender partners. A sum score was created as an index of having sex with risk partners. Since the scores were highly skewed, it was further dichotomized for analysis with 0 for none and 1 for one or more sexual risk partners. Since no female participants reported having sex with females, we did not consider male-female differences when assessing having sex with the same gender persons.

The commercial blood donors were included as a category of high risk partners in the original survey checklist considering the high prevalence rate of HIV/AIDS in China who acquired the infection through unsterilized procedures of blood serum collection and blood cell back infusion by illegal blood collection companies (Kaufman \& Jing, 2002). But no participants reported having sex with this high risk group, this group was excluded. It is worth noting that we used this summary index rather than more detailed sexual risk behavior because our study focused on rural migrants in general, rather than high risk groups (e.g., sex workers or men who have sex with men) with multiple types and high frequencies of risk behaviors. Furthermore, findings from other studies using similar measures indicate this variable as a good proxy of HIV-related sexual risk behaviors (Bolding, Davis, Hart, Sherr, \& Elford, 2005; Nasrullah, Oraka, Chavez, Valverde, \& Dinenno, 2015; Williams \& Latkin, 2005).

Mediators-The Brief Symptom Inventory (BSI), including its five subscales (Derogatis \& Melisaratos, 1983). (1) Somatization (7 items, typical item: "Pains in heart or chest", Cronbach alpha $=0.90)$; (2) Obsessive-compulsive symptoms (6 items, typical item: "Have to check and double-check what you do", Cronbach alpha $=0.84)$; (3) Depression (5 items, 
typical item: "Feeling lonely", Cronbach alpha $=0.87)$; (4) Anxiety (6 items, typical item: "Nervousness or shakiness inside", Cronbach alpha $=0.87$ ); and (5) Hostility (6 items, typical item: "Having urges to break or smash things", Cronbach alpha $=0.87)$. Individual BSI items were rated using a five-point Likert scale with 1 (never) to 5 (always). Mean scores for individual subscales were computed for analysis such that higher scores indicated greater mental health problems. The BSI has adequate reliability and validity, and has been widely used in research globally (Gilbar \& Ben-Zur, 2002; Hwang \& Ting, 2008; LoutsiouLadd, Panayiotou, \& Kokkinos, 2008), including in China (Chang et al., 2005; D. F. K. Wong, He, Leung, Lau, \& Chang, 2008).

Predictor-Migration stress was assessed using the Domestic Migration Stress Questionnaire (DMSQ) (Chen, Yu, Gong, et al., 2015). DMSQ was developed based on the Barcelona Immigration Stress Scale, and was directly tied to the loneliness and acculturation theory (Tomas-Sabado, Qureshi, Antonin, \& Collazos, 2007). The DMSQ consists of 16 items with four subscales: Separation from the place of origin, Rejection in the destination, Lack of self-confidence, and Maladaptation (4 items per subscale). The DMSQ was developed and tested among rural-to-urban migrants in China (alpha $=0.93$ ), and significantly predicted depression, anxiety, somatization, hostility, and obsessive-compulsive symptoms (Chen, Yu, Gong, et al., 2015). Typical items included "Worried so much about my family members and relatives who remain so far away in hometown" for separation, "Being rejected or stared at by others in the city merely because of my appearance or accent" for rejection, "Unconfident about my own capabilities" for lack of self-confidence, and "So many rules and regulations in the city give me a crushing feeling" for maladaptation. Individual items were assessed using a five-point Likert scale varying from 1 (never) to 5 (always). The Cronbach alpha for our data was 0.92. Mean score was computed for analysis, with higher scores indicating greater stress.

Although stress is endogenous in nature, and can be objectively assessed biomarkers, such as serum cortisol (Takahashi et al., 2005), questionnaire assessment is more often used in largescale survey studies (National Addiction \& HIV Data Archive Program, 2013). The DMSQ we used for this study is similar to a number of stress assessment tools often used in research with proven reliability and validity, such as Acculturative Stress Scale for International Students (ASSIS) (Sandhu \& Asrabadi, 1994), Perceived Stress Scale (PSS) (Cohen, Kamarck, \& Mermelstein, 1983), Life Events Checklist (Weathers et al., 2013).

\section{Demographic, migration experience, living conditions, and neighborhood} environment-Four demographic variables were: age (in years), marital status (married and not married), educational attainment (middle school or less, high school or more), and monthly income ( $\leq 2000 \mathrm{RMB}$ and $>2000 \mathrm{RMB} ; 6 \mathrm{RMB} \approx 1 \mathrm{USD}$ ). Migration experience was assessed using the three questions. Question one asked, "How many cities have you migrated to so far?" and the answers were grouped into: 1 city, 2-3 cities, and $\geq 4$ cities; and question two asked, "How many years since you first migrated to this city?"(number of years), and question three asked "What is your purpose to migrate to cities?" with answers of "Self-develop, mainly self-develop, both self-develop and make money, mainly make money, and make money". Two variables were used to assess employment, including days 
worked in a month and hours worked on a typical working day. Three variables for assessing living conditions were: residential location (old town, new town, rural-to-urban joint zone, and suburban), home ownership (rented or non-rented), and living arrangement (living alone or living with others). Three variables for assessing neighborhood environment were: perceived urban residents around (less than a half, half, and more than a half), presence of prior acquaintance (yes/no), and existence of entertainment venues in the neighborhood (none, some, and a great deal) (Lin et al., 2010).

\section{Statistical Analysis}

Descriptive statistics were used to describe the study sample and for simple comparison analysis. These analyses were conducted using the PROC SURVEYMEANS to consider the GIS/GPS-assisted multi-level random sampling design using the sampling option "stratum and cluster" and the sample weight option "weight". This method uses the Taylor expansion method to estimate the sampling errors considering the sample design (Siller \& Tompkins, 2006). Both point estimate and $95 \%$ CIs were computed for key study variables. No overlapping in the estimated $95 \% \mathrm{CI}$ between comparison groups was used as indication of statistically significant difference at $\mathrm{p}<0.05$ level.

The SAS macro "PROCESS" was used to test the proposed a mediation model (Figure 1). In the model, migration stress was used as the predictor variable $X$; Five mental health symptoms (somatization, obsessive-compulsive symptoms, depression, anxiety, and hostility) were used as the mediators $M$, and have sex with high risk partners was used as the outcome $Y$. In the model, a measures the association between the predictor $X$ and the mediator $M ; b$ measures the association between the mediator $M$ and the outcome $Y$; and $c^{\prime}$ measures the association between $X$ and $Y$ controlling for the mediator $M$, known as direct effect. The indirect effect, assessed as $a^{*} b$ provides a measure of the association between $X$ and $Y$ mediated through $M$. These model parameters were all assessed using the SAS macro, including the point and interval $(95 \% \mathrm{CI})$ estimates for the direct and indirect effect and significance test of the indirect effect using the bootstrapping method (A. F. Hayes, 2013; Preacher \& Hayes, 2008). This particular macro is unable to handle complicated multi-level random sampling design, and could not apply sample weight in the computing process. This SAS callable macro is developed to analyze the mediation and moderation model, and has been widely used in research (Gutiérrez-Doña, Lippke, Renner, Kwon, \& Schwarzer, 2009; A.F. Hayes, 2012; Preacher \& Hayes, 2004). The variables age, marital status, education, and number of cities migrated and number of years migrated were included as covariates in the mediation modeling analyses. Type I error was set at $\mathrm{p}<0.05$ (two-sided) for all statistical analyses. Statistical analyses were conducted using the commercial software SAS, version 9.4 (SAS Institute, Cary, NC).

\section{Results}

\section{Characteristics of the Study Sample}

Results in Table 1 show that among the 1,293 rural-to-urban migrants included in the analysis, 661 (51.12\%) were male, $995(77.13 \%)$ were married, 417 (32.33\%) had attained a high school education or more, 289 (22.35\%) went to city for self-development, worked 
24.87 (8.27) days per month, 9.43 (3.59) hours per day and 473 (36.58\%) had an income of more than 2,000 RMB per month. The mean age of the sample was 32.31 ( $\mathrm{SD}=7.97) .784$ $(60.63 \%)$ of the migrants had migrated to more than one city, $621(48.03 \%)$ were located in the old town, 841 (65.04\%) were living in rented homes, with $783(60.56 \%)$ living together. In terms of the neighborhood environment, $813(62.88 \%)$ perceived that half or more of the people surrounding them were urbanites, nearly $80 \%$ of the migrants perceived presence of prior acquaintance nearby, and $81.59 \%$ found at least some entertainment venues nearby.

\section{Having Sex with High Risk Partners among Rural-to-Urban Migrants}

Results from our analysis indicated that among the total migrant sample, $6.84 \%[5.56,8.13]$ of males and $6.19 \%[4.54,7.83]$ of females reported having had sex with at least one high risk partner. Results in Table 2 show that among males, migrants who had sex with high risk partners relative to those who did not, scored significantly higher on Migration Stress (2.96 vs. $2.58, \mathrm{p}<0.05)$, total BSI ( 2.70 vs. $1.97, \mathrm{p}<0.05)$, somatization ( 2.69 vs. $1.88, \mathrm{p}<0.05)$, obsessive-compulsive symptoms ( 2.72 vs. 2.13 , p<0.05), depression ( 2.75 vs. $1.99, \mathrm{p}<0.05$ ), anxiety ( 2.68 vs. $1.87, \mathrm{p}<0.05)$, and hostility ( 2.70 vs. 1.96 , p<0.05) Among female migrants, similar results were observed.

\section{Mediation Analysis}

Results in Table 3 indicate a significant indirect ( $a * b)$ effect of the poor mental health problems in mediating the impact of migration stress on having sex with high risk partners for male migrant sample, including the total BSI $(0.41, \mathrm{p}<.05)$, somatization $(0.32, \mathrm{p}<.05)$, obsessive-compulsive disorder $(0.31, \mathrm{p}<.05)$, depression $(0.45, \mathrm{p}<.05)$, anxiety $(0.41, \mathrm{p}<.05)$, and hostility $(0.35, \mathrm{p}<.05)$. It is worth noting that none of the direct effect $\mathrm{c}^{\prime}$ from migration stress $\mathrm{X}$ on high risk partner sex $\mathrm{Y}$ was statistically significant at $\mathrm{p}<.05$ level, suggesting that the relationship between the two was "completely" mediated through poor mental health.

Relative to males, the mediation effects for females was not statistically significant, except one BSI component-somatization (0.40, $\mathrm{p}<.05)$. Similar associations were also observed when the migration stress components, including separation, rejection, lack of selfconfidence and maladaptation, were analyzed separately using the same mediation model.

\section{Discussion}

As the HIV epidemic enters its fourth decade (UNAIDS \& WHO, 2013), a new risk that may continue to fuel the spread of the virus is the growing trends in domestic and international migration (Lurie et al., 2003; Zhang et al., 2013). The process of migration is stressful since it involves with separation from the family and social contacts in the place of origin, and acculturation/assimilation to the culture and lifestyle in the destination (Chen, Yu, Gong, et al., 2015; Rudmin, 2003; Sher \& Vilens, 2010; Winkelman, Chaney, \& Bethel, 2013; D. F. K Wong, Lam, Yan, \& Hung, 2004). An in-depth understanding of the relationship between migration stress, mental health, and HIV-related behaviors among migrant population is of great significance for the development of more effective HIV prevention and control policies and intervention programs. In this study, we investigated the complex relationship between migration stress, poor mental health and engagement in sex 
with high risk partners among rural migrants with a sample selected in Wuhan, China. Our research findings support the notion that migration may facilitate HIV transmission through the mediation path from migration stress to poor mental health, further to engaging in sex with high risk partners (Vitinghoff et al., 1999; H. Yang et al., 2005; X. Yang, Derlega, \& Luo, 2007).

Findings of this study suggest that engagement in sex with high risk partners may be a concern for HIV prevention among rural-to-urban migrants in China. According to our study findings, among rural-to-urban migrants in Wuhan, approximately $7 \%$ of males and $6 \%$ of females engaged in sex with at least one risk partner in the past year. Although the rates are not high, given the large number of migrants (approximately 2 million in Wuhan and 270 million in China), we cannot ignore the influence of this sexual risk behavior on HIV spread.

A very significant finding of this study is the demonstration of the role of poor mental health in mediating the relationship between migration stress and sexual risk behaviors, particularly for male migrants. In addition to the poor mental health status in general as measured by BSI, the associations between migration stress and BSI, including its main components (i.e., somatization, obsessive-compulsive disorder, depression, anxiety, and hostility) were all statistically significant. Furthermore, there was no direct relationship between migration stress and engagement in sex with high-risk partners because the relationship was fully mediated by mental health status. The lack of a direct effect between stress on high-risk partner sex has been reported in previous studies with data collected in Russia and the United States (Folkman et al., 1992; Mazzaferro et al., 2006). Findings from our study and others appear to suggest that engagement in sex with high risk partners may serve as negative coping strategy to deal with stress (Folkman et al., 1992; Sudhinaraset et al., 2012; T. Yang et al., 2009; X. Yang et al., 2015). As for female migrants, they may have alternative approaches rather than having sex with high risk partners to deal with stress and mental health problems. Further study is needed to investigate this issue in the future.

\section{Implication for the development of HIV prevention and control policies in China}

If the finding of our study can be confirmed, it will be of great significance for informing intervention research, especially among male migrant population. Current HIV control programs and policies in Wuhan as well as other parts in China mainly concentrated on promoting the condom use among high risk populations (e.g. commercial sex workers, drug users, men who have sex with men), increasing the active HIV testing, and strengthening the adherence of HIV treatment for people living with HIV/AIDS (Wu, Sullivan, Wang, Rotheram-Borus, \& Detels, 2007). No attention has been paid to mental health, particularly mental health status among the large number of rural-to-urban migrants who are consistently under stress in urban settings. If our finding regarding the mediation effect can be approved through longitudinal study, we can conclude that although migration stress is not avoidable, a migrant may not engage in sex with high risk partners if measures can be taken to deal with stress and poor mental health.

A number of intervention programs targeting the poor mental health are reported, such as the combined cognitive-behavioral family education intervention (Asarnow, Scott, \& Mintz, 2002), the group music therapy (Choi, Lee, \& Lim, 2008), the community-based 
intervention and group activities (Oyama et al., 2006), the social group intervention (Gater et al., 2010). These intervention programs may be useful to health rural migrants in China to prevent the spread of HIV. However, none of these method has been adapted for use in Wuhan to improve mental health among rural-to-urban migrants. Findings from our study provide some preliminary data supporting the development of new and adaptation of existing intervention programs and policies for rural migrants in Wuhan to curb the growing HIV epidemic there.

There are limitations to this study that need further research. First, this study was crosssectional in nature, and causal relationships cannot be ascertained without longitudinal studies. Secondly, data for this analysis was collected in one city in China, and caution is needed when the findings of this study are generalized to other cities within or outside China. Third, the study sample was selected from a general rather than high risk population, and few females reported having engaged in sex with high risk partners. Fourth, other detailed risk sexual behaviors (e.g. unprotected sexual behavior, commercial sex work experience) were not measured in this study. Last but not the least, we could not pick up the commercial sex workers by asking if they had sex with sex workers in this study. Despite these limitations, this study is the first to investigate the mediation role of poor mental health in the relationship between migration stress and HIV risk sexual behaviors among Chinese rural migrants. Findings in this study provide some new data supporting HIV prevention and control policies targeting rural migrant in China.

\section{Acknowledgments}

This work was funded by the National Institutes of Health (Award \#: R01 MH086322). We are very grateful to other researchers and community health workers who participated in data collection and data processing. This work will not be possible without their dedicated efforts and assistance.

Funding: This study was funded by a research grant from the National Institutes of Health (Award \#: R01 MH086322).

\section{References}

Amirkhanian YA, Kuznetsova AV, Kelly JA, DiFranceisco WJ, Musatov VB, Avsukevich NA, ... McAuliffe TL. Male labor migrants in Russia: HIV risk behavior levels, contextual factors, and prevention needs. Journal of Immigrant and Minority Health. 2011; 13(5):919-928. [PubMed: 20690041]

Asarnow JR, Scott CV, Mintz J. A combined cognitive-behavioral family education intervention for depression in children: A treatment development study. Cognitive Therapy and Research. 2002; 26(2):221-229.

Berry JW. Immigration, acculturation, and adaptation. Applied Psychology. 1997; 46(1):5-34.

Bolding G, Davis M, Hart G, Sherr L, Elford J. Gay men who look for sex on the Internet: is there more HIV/STI risk with online partners? AIDS. 2005; 19(9):961-968. [PubMed: 15905678]

Brody, Gene H., Chen, Yi-Fu, Kogan, Steven M. A cascade model connecting life stress to risk behavior among rural African American emerging adults. Development and psychopathology. 2010; 22(03):667-678. [PubMed: 20576186]

Carpiano RM, Kelly BC, Easterbrook A, Parsons JT. Community and drug use among gay men the role of neighborhoods and networks. Journal of Health and Social Behavior. 2011; 52(1):74-90. [PubMed: 21362613] 
Chang DF, Myers HF, Yeung A, Zhang Y, Zhao J, Yu S. Shenjing shuairuo and the DSM-IV: Diagnosis, distress, and disability in a Chinese primary care setting. Transcultural Psychiatry. 2005; 42(2):204-218. [PubMed: 16114583]

Chen X, Gong J, Yu B, Li S, Striley C, Yang N, Li F. Constructs, concept mapping and psychometric assessment of the Concise Scale of Individualism-Collectivism. Social Behavior and Personality: an International Journal. 2015; 43(4):667-684.

Chen X, Stanton B, Gong J, Fang X, Li X. Personal Social Capital Scale: an instrument for health and behavioral research. Health Educ Res. 2009; 24(2):306-317. cyn020[pii]. DOI: 10.1093/her/cyn020 [PubMed: 18469318]

Chen X, Yu B, Gong J, Zeng J, MacDonell K. The Domestic Migration Stress Questionnaire (DMSQ): development and psychometric assessment. Journal of Social Sciences Studies. 2015; 2(2):117133.

Chen X, Yu B, Zhou D, Zhou W, Gong J, Li S, Stanton B. A Comparison of the Number of Men Who Have Sex with Men among Rural-To-Urban Migrants with Non-Migrant Rural and Urban Residents in Wuhan, China: A GIS/GPS-Assisted Random Sample Survey Study. Plos One. 2015; 10(8)doi: 10.1371/journal.pone.0134712

Cheung NW. Social stress, locality of social ties and mental well-being: The case of rural migrant adolescents in urban China. Health \& Place. 2014; 27:142-154. [PubMed: 24607873]

Choi AN, Lee MS, Lim HJ. Effects of group music intervention on depression, anxiety, and relationships in psychiatric patients: A pilot study. The Journal of alternative and complementary medicine. 2008; 14(5):567-570. [PubMed: 18564958]

Cochran, WG. Sampling techniques. 3. New York: Wiley; 1977.

Cohen, Sheldon, Kamarck, Tom, Mermelstein, Robin. A global measure of perceived stress. Journal of health and social behavior. 1983:385-396. [PubMed: 6668417]

Deren S, Kang SY, Mino M, Guarino H. Migrant drug users: predictors of HIV-related sexual and injection risk behaviors. Journal of Immigrant and Minority Health. 2010; 12(2):179-186. [PubMed: 19093210]

Derogatis LR, Melisaratos N. The brief symptom inventory: an introductory report. Psychological Medicine. 1983; 13(03):595-605. [PubMed: 6622612]

Deuba, Keshab, Ekström, Anna Mia, Shrestha, Rachana, Ionita, George, Bhatta, Laxmi, Karki, Deepak Kumar. Psychosocial health problems associated with increased HIV risk behavior among men who have sex with men in Nepal: a cross-sectional survey. PloS one. 2013; 8(3):e58099. [PubMed: 23516434]

Du, Hongfei, Li, Xiaoming. Acculturation and HIV-related sexual behaviours among international migrants: A systematic review and meta-analysis. Health psychology review. 2015; 9(1):103-122. [PubMed: 25793493]

Folkman S, Chesney MA, Pollack L, Phillips C. Stress, coping, and high-risk sexual behavior. Health Psychology. 1992; 11(4):218. [PubMed: 1396489]

Gater R, Waheed W, Husain N, Tomenson B, Aseem S, Creed F. Social intervention for British Pakistani women with depression: randomised controlled trial. The British Journal of Psychiatry. 2010; 197(3):227-233. [PubMed: 20807969]

Gilbar O, Ben-Zur H. Adult Israeli community norms for the brief symptom inventory (BSI). International Journal of Stress Management. 2002; 9(1):1-10.

Grove, RM. Survey Methodology. New York: Wiley-Interscience, A John Wiley \& Sons, Inc; 2004.

Gutiérrez-Doña B, Lippke S, Renner B, Kwon S, Schwarzer R. Self-Efficacy and Planning Predict Dietary Behaviors in Costa Rican and South Korean Women: Two Moderated Mediation Analyses. Applied Psychology: Health and Well-Being. 2009; 1(1):91-104.

Hayes AF. PROCESS: A versatile computational tool for observed variable mediation, moderation, and conditional process modeling. 2012

Hayes, AF. Introduction to mediation, moderation, and conditional process analysis: A regressionbased approach. Guilford Press; 2013.

Hovey JD, Magana C. Acculturative stress, anxiety, and depression among Mexican immigrant farmworkers in the midwest United States. Journal of Immigrant Health. 2000; 2(3):119-131. DOI: 10.1023/A:1009556802759 [PubMed: 16228745] 
Hwang WC, Ting JY. Disaggregating the effects of acculturation and acculturative stress on the mental health of Asian Americans. Cultural Diversity and Ethnic Minority Psychology. 2008; 14(2):147. [PubMed: 18426287]

Kaufman J, Jing J. China and AIDS—The time to act is now. Science. 2002; 296(5577):2339-2340. [PubMed: 12089428]

Landry PF, Shen M. Reaching migrants in survey research: the use of the global positioning system to reduce coverage bias in China. Political Analysis. 2005; 13(1):1-22.

Lin C, Li L, Wu Z, Guan J, Xu Y, Wu D. ... NIMH Collaborative HIV/STD Prevention Trial Group. Entertainment venue visiting and commercial sex in China. International Journal of Sexual Health. 2010; 22(1):5-13. [PubMed: 25132901]

Loutsiou-Ladd A, Panayiotou G, Kokkinos CM. A review of the factorial structure of the Brief Symptom Inventory (BSI): Greek evidence. International Journal of Testing. 2008; 8(1):90-110.

Lurie MN, Williams BG, Zuma K, Mkaya-Mwamburi D, Garnett GP, Sturm AW, ... Karim SS. The impact of migration on HIV-1 transmission in South Africa: a study of migrant and nonmigrant men and their partners. Sexually Transmitted Diseases. 2003; 30(2):149-156. [PubMed: 12567174]

Mazzaferro KE, Murray PJ, Ness RB, Bass DC, Tyus N, Cook RL. Depression, stress, and social support as predictors of high-risk sexual behaviors and STIs in young women. Journal of Adolescent Health. 2006; 39(4):601-603. [PubMed: 16982400]

Muñoz-Laboy, Miguel, Severson, Nicolette, Bannan, Shauna. Occupations, social vulnerability and HIV/STI risk: The case of bisexual Latino men in the New York City metropolitan area. Global public health. 2014; 9(10):1167-1183. [PubMed: 25299059]

Nasrullah M, Oraka E, Chavez PR, Valverde E, Dinenno E. Nonvolitional sex and HIV-related sexual risk behaviours among MSM in the United States. AIDS. 2015; 29(13):1673-1680. [PubMed: 26372278]

National Addiction \& HIV Data Archive Program. National Survey on Drug Use and Health, 2013. 2013. Retrieved October 5, 2015, from http://www.icpsr.umich.edu/icpsrweb/NAHDAP/studies/ 35509 ? archive $=$ NAHDAP $\&$ searchSource $=$ revise $\& q=N S D U H \% 2 C+2013$

National Bureau of Statistics of the People's Republic of China. National rural-to-urban migrants surveillance report in 2013. 2014. Retrieved Feb 2, 2015, from http://www.stats.gov.cn/tjsj/zxfb/ 201405/t20140512_551585.html

Oyama H, Ono Y, Watanabe N, Tanaka E, Kudoh S, Sakashita T, ... Nakamura K. Local community intervention through depression screening and group activity for elderly suicide prevention. Psychiatry and Clinical Neurosciences. 2006; 60(1):110-114. [PubMed: 16472368]

Park SY, Anastas J, Shibusawa T, Nguyen D. The Impact of Acculturation and Acculturative Stress on Alcohol Use Across Asian Immigrant Subgroups. Substance Use \& Misuse. 2014; 49(8):922-931. [PubMed: 24779491]

Ponizovsky AM, Ritsner MS. Patterns of loneliness in an immigrant population. Comprehensive Psychiatry. 2004; 45(5):408-414. [PubMed: 15332205]

Preacher KJ, Hayes AF. SPSS and SAS procedures for estimating indirect effects in simple mediation models. Behavior research methods, instruments, \& computers. 2004; 36(4):717-731.

Preacher KJ, Hayes AF. Asymptotic and resampling strategies for assessing and comparing indirect effects in multiple mediator models. Behavior Research Methods. 2008; 40(3):879-891. [PubMed: 18697684]

Revollo HW, Qureshi A, Collazos F, Valero S, Casas M. Acculturative stress as a risk factor of depression and anxiety in the Latin American immigrant population. International Review of Psychiatry. 2011; 23(1):84-92. [PubMed: 21338303]

Rudmin FW. Critical history of the acculturation psychology of assimilation, separation, integration, and marginalization. Review of general psychology. 2003; 7(1):3.

Sandhu DS, Asrabadi BR. Development of an Acculturative Stress Scale for International Students: preliminary findings. Psychol Rep. 1994; 75(1 Pt 2):435-448. [PubMed: 7809315]

Sher, L., Vilens, A. Immigration and mental health : stress, psychiatric disorders, and suicidal behavior among immigrants and refugees. Hauppauge, N.Y: Nova Science; 2010. 
Siller, AB., Tompkins, L. The big four: analyzing complex sample survey data using SAS, SPSS, STATA, and SUDAAN. Paper presented at the Proceedings of the Thirty-first Annual SAS® Users Group International Conference; 2006.

Sirin SR, Ryce P, Gupta T, Rogers-Sirin L. The role of acculturative stress on mental health symptoms for immigrant adolescents: a longitudinal investigation. Developmental Psychology. 2013; 49(4): 736-748. DOI: 10.1037/a0028398 [PubMed: 22563676]

Spiegelman D, Gray R. Cost-efficient study designs for binary response data with Gaussian covariate measurement error. Biometrics. 1991; 47(3):851-869. [PubMed: 1789885]

Statistical Bureau of Wuhan. Wuhan Statistical Yearbook-2012. Beijing: China Statistics Press; 2012.

Sudhinaraset M, Mmari K, Go V, Blum RW. Sexual attitudes, behaviours and acculturation among young migrants in Shanghai. Culture, Health \& Sexuality. 2012; 14(9):1081-1094.

Takahashi T, Ikeda K, Ishikawa M, Kitamura N, Tsukasaki T, Nakama D, Kameda T. Anxiety, reactivity, and social stress-induced cortisol elevation in humans. Neuroendocrinology Letters. 2005; 26(4):351-354. [PubMed: 16136010]

Thomas TN. Acculturative stress in the adjustment of immigrant families. Journal of Social Distress and the Homeless. 1995; 4(2):131-142.

Tomas-Sabado J, Qureshi A, Antonin M, Collazos F. Construction and preliminary validation of the Barcelona Immigration Stress Scale. Psychol Rep. 2007; 100(3 Pt 1):1013-1023. [PubMed: 17688120]

UNAIDS, \& WHO. Global report: UNAIDS report on the global AIDS epidemic 2013. Geneva: UNAIDS; 2013.

Vitinghoff E, Douglas J, Judon F, McKiman D, MacQueen K, Buchinder SP. Per-contact risk of human immunodificiency virus tramnsmision between male sexual partners. American Journal of Epidemiology. 1999; 150(3):306-311. [PubMed: 10430236]

Weathers, FW., Blake, DD., Schnurr, PP., Kaloupek, DG., Marx, BP., Keane, TM. The life events checklist for DSM-5 (LEC-5). Instrument available from the National Center for PTSD. 2013. atwww.ptsd.va.gov

Weine SM, Kashuba AB. Labor migration and HIV risk: a systematic review of the literature. AIDS and Behavior. 2012; 16(6):1605-1621. [PubMed: 22481273]

Williams CT, Latkin CA. The role of depressive symptoms in predicting sex with multiple and highrisk partners. JAIDS Journal of Acquired Immune Deficiency Syndromes. 2005; 38(1):69-73. [PubMed: 15608528]

Winkelman SB, Chaney EH, Bethel JW. Stress, Depression and Coping among Latino Migrant and Seasonal Farmworkers. International Journal of Environmental Research and Public Health. 2013; 10(5):1815-1830. [PubMed: 23644829]

Wong DFK, Lam D, Yan P, Hung M. The impacts of acculturative stress and social competence on the mental health of Mainland Chinese immigrant youth in Hong Kong. British Journal of Social Work. 2004; 34(7):1009-1024. DOI: 10.1093/Bjsw/Bch126

Wong DFK, Chang YL. Mental health of Chinese migrant workers in factories in Shenzhen, China: Effects of migration stress and social competence. Social Work in Mental Health. 2010; 8(4):305318.

Wong DFK, He X, Leung G, Lau Y, Chang Y. Mental health of migrant workers in China: prevalence and correlates. Social Psychiatry and Psychiatric Epidemiology. 2008; 43(6):483-489. [PubMed: 18398559]

Wu Z, Sullivan SG, Wang Y, Rotheram-Borus MJ, Detels R. Evolution of China's response to HIV/ AIDS. The Lancet. 2007; 369(9562):679-690.

Yang H, Li X, Stanton B, Chen X, Liu H, Fang X, ... Mao R. HIV-related risk factors associated with commercial sex among female migrants in China. Health Care for Women International. 2005; 26(2):134-148. [PubMed: 15804913]

Yang T, Wang W, Abdullah AS, Beard J, Cao C, Shen M. HIV/AIDS-related sexual risk behaviors in male rural-to-urban migrants in China. Social Behavior and Personality: an international journal. 2009; 37(3):419-432.

Yang X. Temporary migration and HIV risk behaviors in China. Environment and Planning A. 2006; 38(8):1527. 
Yang X, Derlega VJ, Luo H. Migration, behaviour change and HIV/STD risks in China. AIDS Care. 2007; 19(2):282-288. [PubMed: 17364411]

Yang, X., Kelly, BC., Yang, T. Sociology of Health \& Illness. 2015. Together we have fun: native-place networks and sexual risk behaviours among Chinese male rural-urban migrants.

Yu B, Chen X, Li S. Globalization, cross-culture stress and health. Chinese Journal of Epidemiology. 2014; 35(3):338-341. [PubMed: 24831640]

Zhang L, Chow EP, Jahn HJ, Kraemer A, Wilson DP. High HIV prevalence and risk of infection among rural-to-urban migrants in various migration stages in China: a systematic review and metaanalysis. Sexually Transmitted Diseases. 2013; 40(2):136-147. [PubMed: 23321993] 


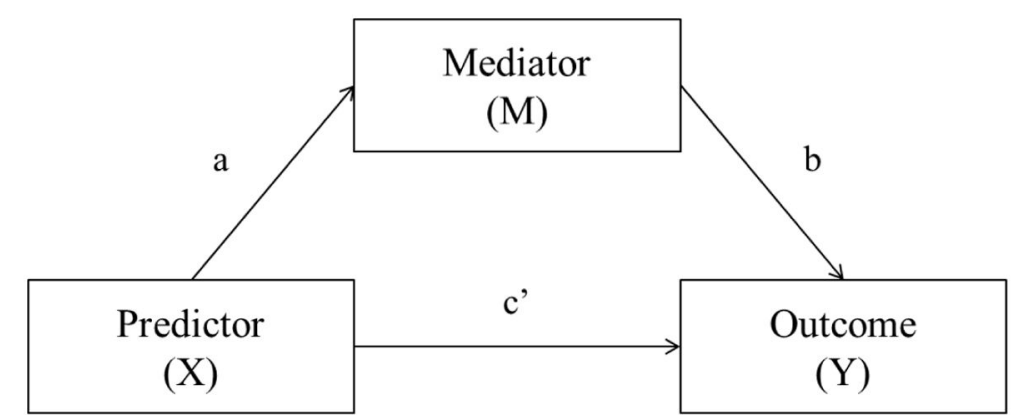

Figure 1. Schematic mediation analysis model

Note: Y: Outcome variable, having sex with high risk partners; M: Mediator, five mental health symptoms (somatization, obsessive-compulsive, depression, anxiety, and hostility); X: Predictor, migration stress. 


\section{Table 1}

Characteristics of the Study Sample

\begin{tabular}{|c|c|c|c|}
\hline \multirow{2}{*}{ Variables } & \multicolumn{2}{|c|}{ Gender } & \multirow{2}{*}{ Total } \\
\hline & Male & Female & \\
\hline Total, $\mathbf{n}(\%)$ & $661(51.12)$ & $632(48.88)$ & $1293(100.00)$ \\
\hline \multicolumn{4}{|l|}{ Age, n (\%) } \\
\hline $18-35$ & $417(63.09)$ & $378(59.81)$ & $795(61.48)$ \\
\hline $36-45$ & $244(36.91)$ & $254(40.19)$ & $498(38.52)$ \\
\hline Mean (SD) & $31.85(8.24)$ & $32.80(7.66)$ & $32.31(7.97)$ \\
\hline \multicolumn{4}{|l|}{ Marital status, n (\%) } \\
\hline Not married & $198(30.05)$ & $97(15.37)$ & $295(22.87)$ \\
\hline Married & $461(69.95)$ & $534(84.63)$ & $995(77.13)$ \\
\hline \multicolumn{4}{|l|}{ Education attainment, n (\%) } \\
\hline Middle school or less & $420(63.73)$ & $453(71.79)$ & $873(67.67)$ \\
\hline High school or more & $239(36.27)$ & $178(28.21)$ & $417(32.33)$ \\
\hline \multicolumn{4}{|l|}{ Purpose for being in the city } \\
\hline Self-develop & $162(24.51)$ & $127(20.09)$ & $289(22.35)$ \\
\hline Mainly self-develop & $182(27.53)$ & $174(27.53)$ & $356(27.53)$ \\
\hline Both self-develop and make money & $76(11.50)$ & $72(11.39)$ & $148(11.45)$ \\
\hline Mainly make money & $153(23.15)$ & $147(23.26)$ & $300(23.20)$ \\
\hline Make money & $88(13.31)$ & $112(17.72)$ & $200(15.47)$ \\
\hline \multicolumn{4}{|l|}{ Days worked per month } \\
\hline Mean (SD) & $26.13(6.27)$ & $23.56(9.77)$ & $24.87(8.27)$ \\
\hline \multicolumn{4}{|l|}{ Hours worked per day } \\
\hline Mean (SD) & $10.04(3.12)$ & $8.80(3.94)$ & $9.43(3.59)$ \\
\hline \multicolumn{4}{|l|}{ Monthly income (RMB), n (\%) } \\
\hline $\mathfrak{2}, 000$ & $338(51.13)$ & $482(76.27)$ & $820(63.42)$ \\
\hline$>2,000$ & $323(48.87)$ & $150(23.73)$ & $473(36.58)$ \\
\hline \multicolumn{4}{|l|}{ No. of cities migrated, $n(\%)$} \\
\hline 1 & $209(31.62)$ & $300(47.47)$ & $509(39.37)$ \\
\hline $2-3$ & $266(40.24)$ & $274(43.35)$ & $540(41.76)$ \\
\hline 4 or more & $186(28.14)$ & $58(9.18)$ & $244(18.87)$ \\
\hline \multicolumn{4}{|l|}{ Living conditions, $n(\%)$} \\
\hline \multicolumn{4}{|l|}{ Residential locations } \\
\hline Old town & $313(47.35)$ & $308(48.73)$ & $621(48.03)$ \\
\hline New town & $125(18.91)$ & $120(18.99)$ & $245(18.95)$ \\
\hline Rural-urban joint zone & $121(18.31)$ & $106(16.77)$ & $227(17.56)$ \\
\hline Suburban & $102(15.43)$ & $98(15.51)$ & $200(15.47)$ \\
\hline \multicolumn{4}{|l|}{ Home ownership } \\
\hline Rental & $414(62.63)$ & $427(67.56)$ & $841(65.04)$ \\
\hline Non-rental & $247(37.37)$ & $205(32.44)$ & $452(34.96)$ \\
\hline
\end{tabular}

Sex Res Social Policy. Author manuscript; available in PMC 2018 December 01. 


\begin{tabular}{|c|c|c|c|}
\hline \multirow{2}{*}{ Variables } & \multicolumn{2}{|c|}{ Gender } & \multirow{2}{*}{ Total } \\
\hline & Male & Female & \\
\hline Living alone & $289(43.72)$ & $221(34.97)$ & $510(39.44)$ \\
\hline Living with others & $372(56.28)$ & $411(65.03)$ & $783(60.56)$ \\
\hline \multicolumn{4}{|c|}{ Neighborhood environment, $\mathrm{n}(\%)$} \\
\hline \multicolumn{4}{|l|}{ Perceived urbanites around } \\
\hline Less than half & $267(40.39)$ & $213(33.70)$ & $480(37.12)$ \\
\hline Half & $135(20.42)$ & $144(22.78)$ & $279(21.58)$ \\
\hline More than half & $259(39.18)$ & $275(43.51)$ & $534(41.30)$ \\
\hline \multicolumn{4}{|c|}{ Presence of prior acquaintances } \\
\hline Yes & $534(80.79)$ & $497(78.64)$ & $1031(79.74)$ \\
\hline \multicolumn{4}{|c|}{ Existence of entertainment venues } \\
\hline None & $117(17.70)$ & $121(19.15)$ & $238(18.41)$ \\
\hline Some & $427(64.60)$ & $406(64.24)$ & $833(64.42)$ \\
\hline A great deal & $117(17.70)$ & $105(16.61)$ & $222(17.17)$ \\
\hline \multicolumn{4}{|l|}{ Migration stress } \\
\hline Mean (SD) & $2.61(0.70)$ & $2.62(0.63)$ & $2.62(0.67)$ \\
\hline \multicolumn{4}{|l|}{ BSI, Mean (SD) } \\
\hline Total & $1.96(0.66)$ & $2.06(0.62)$ & $2.01(0.64)$ \\
\hline Somatization & $1.91(0.71)$ & $1.96(0.70)$ & $1.93(0.70)$ \\
\hline Obsessive-compulsive & $2.12(0.69)$ & $2.28(0.65)$ & $2.20(0.68)$ \\
\hline Depression & $1.99(0.74)$ & $2.08(0.73)$ & $2.03(0.73)$ \\
\hline Anxiety & $1.88(0.66)$ & $1.98(0.64)$ & $1.93(0.65)$ \\
\hline Hostility & $1.90(0.69)$ & $1.99(0.64)$ & $1.94(0.67)$ \\
\hline \multicolumn{4}{|c|}{ Sex with high risk partners, $n(\%)$} \\
\hline Yes & $51(7.72)$ & $20(3.16)$ & $71(5.49)$ \\
\hline
\end{tabular}

Sex Res Social Policy. Author manuscript; available in PMC 2018 December 01. 
Table 2

Comparison of the Migrants Who Reported Having and not Having Sex with High Risk Partners

\begin{tabular}{|c|c|c|c|}
\hline \multirow{2}{*}{ Variables } & \multicolumn{2}{|c|}{ Had sex with high risk partners } & \multirow{2}{*}{ Total } \\
\hline & Yes & No & \\
\hline \multicolumn{4}{|l|}{ Male $(n=661)$} \\
\hline$\%[95 \% \mathrm{CI}]$ & $6.84[5.56,8.13]^{*}$ & $93.16[91.87,94.44]$ & $100.00[100.00,100.00]$ \\
\hline \multicolumn{4}{|l|}{ Migration stress } \\
\hline Mean $[95 \% \mathrm{CI}]$ & $2.96[2.84,3.09]^{*}$ & $2.58[2.52,2.65]$ & $2.61[2.55,2.67]$ \\
\hline \multicolumn{4}{|l|}{ BSI score, Mean [95\%CI] } \\
\hline Total & $2.70[2.52,2.89]^{*}$ & $1.97[1.90,2.03]$ & $2.02[1.95,2.08]$ \\
\hline Somatization & $2.69[2.49,2.89]^{*}$ & $1.88[1.82,1.95]$ & $1.94[1.87,2.01]$ \\
\hline Obsessive-compulsive & $2.72[2.55,2.89]^{*}$ & $2.13[2.06,2.21]$ & $2.17[2.10,2.24]$ \\
\hline Depression & $2.75[2.56,2.94]^{*}$ & $1.99[1.91,2.07]$ & $2.04[1.97,2.11]$ \\
\hline Anxiety & $2.68[2.48,2.87]^{*}$ & $1.87[1.81,1.94]$ & $1.93[1.87,1.99]$ \\
\hline Hostility & $2.70[2.52,2.88]^{*}$ & $1.96[1.88,2.03]$ & $2.01[1.94,2.08]$ \\
\hline \multicolumn{4}{|l|}{ Female (n=632) } \\
\hline$\%[95 \% \mathrm{CI}]$ & $6.19[4.54,7.83]^{*}$ & $93.81[92.17,95.46]$ & $100.00[100.00,100.00]$ \\
\hline \multicolumn{4}{|l|}{ Migration stress } \\
\hline Mean $[95 \% \mathrm{CI}]$ & $3.54[3.30,3.77]^{*}$ & $2.67[2.59,2.75]$ & $2.72[2.65,2.80]$ \\
\hline \multicolumn{4}{|l|}{ BSI score, Mean [95\%CI] } \\
\hline Total & $2.68[2.56,2.80]^{*}$ & $2.04[1.96,2.13]$ & $2.08[2.00,2.16]$ \\
\hline Somatization & $2.78[2.68,2.89]^{*}$ & $1.93[1.84,2.02]$ & $1.98[1.90,2.07]$ \\
\hline Obsessive-compulsive & $2.88[2.75,3.01]^{*}$ & $2.28[2.19,2.38]$ & $2.32[2.23,2.41]$ \\
\hline Depression & $2.66[2.45,2.87]^{*}$ & $2.05[1.95,2.15]$ & $2.09[2.00,2.18]$ \\
\hline Anxiety & $2.50[2.41,2.58]^{*}$ & $1.96[1.87,2.04]$ & $1.99[1.91,2.07]$ \\
\hline Hostility & $2.59[2.47,2.71]^{*}$ & $2.00[1.92,2.08]$ & $2.04[1.96,2.11]$ \\
\hline
\end{tabular}

Note:

${ }^{*}<0.05$. Computed using PROC SURVEYMEANS. 


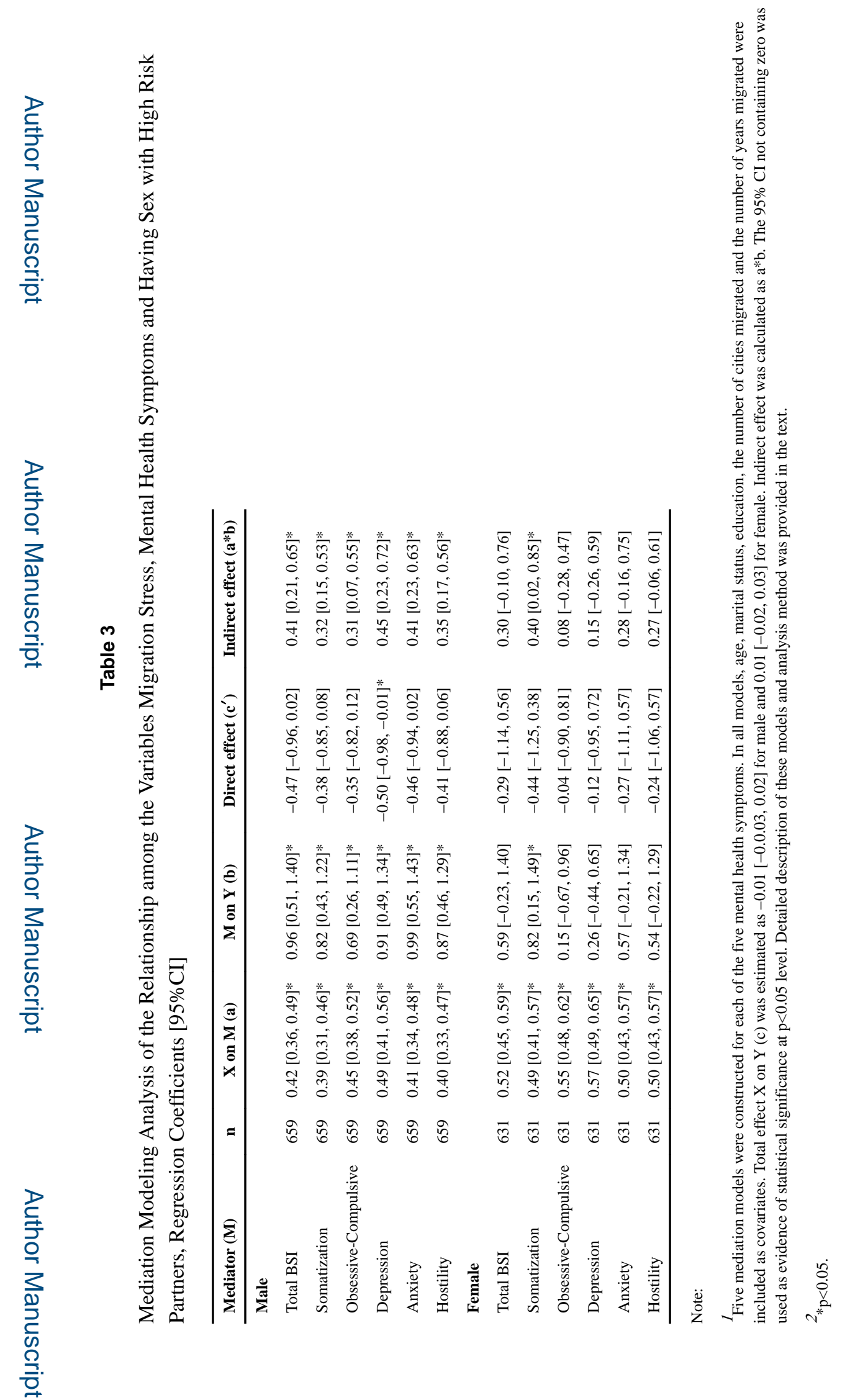

Sex Res Social Policy. Author manuscript; available in PMC 2018 December 01. 